Revista de

Estudios

Kantianos

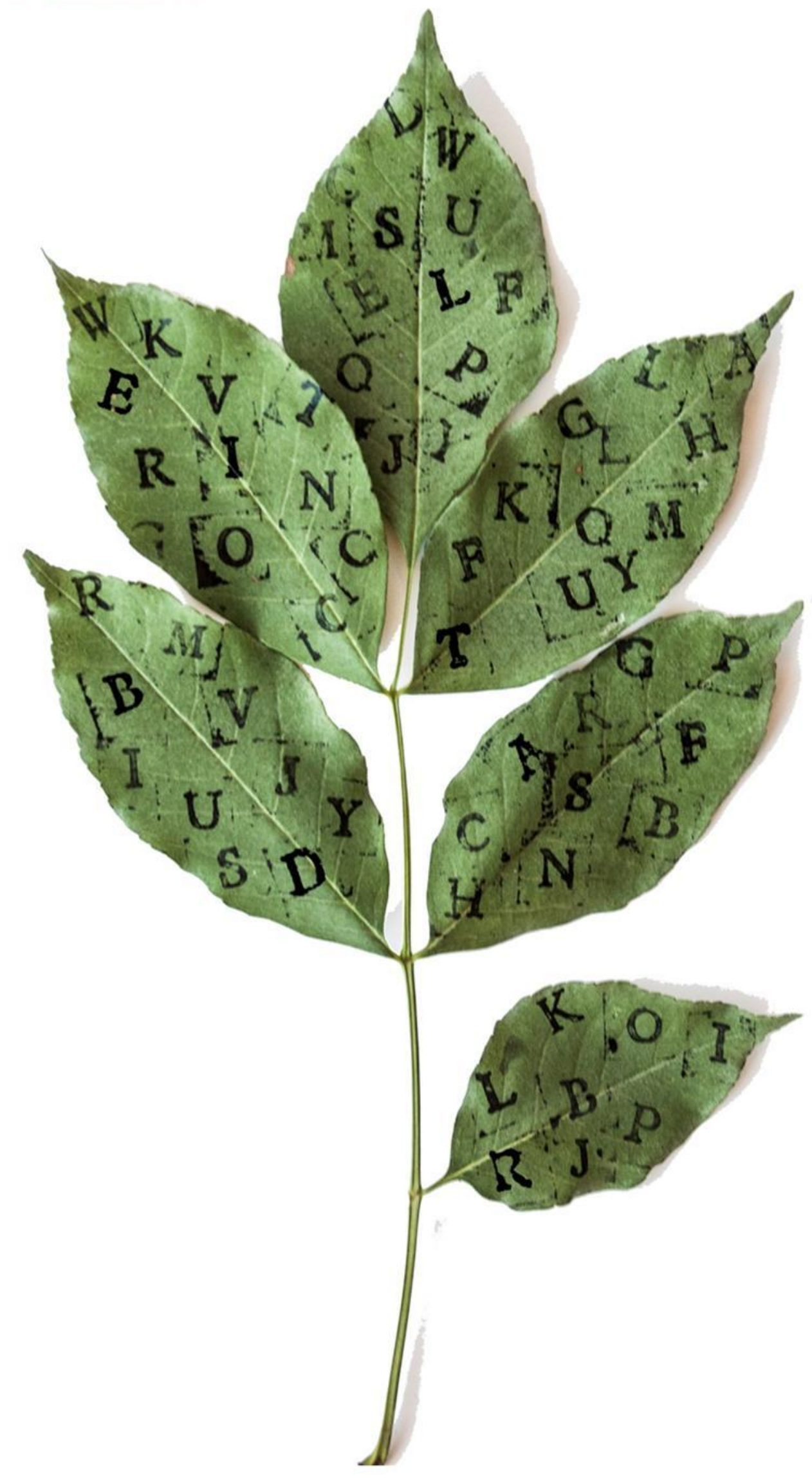


Revista de Estudios Kantianos 


\section{Revista de Estudios Kantianos}

Publicación internacional de la Sociedad de Estudios Kantianos en Lengua Española Internationale Zeitschrift der Gesellschaft für Kant-Studien in Spanischer Sprache International Journal of the Society of Kantian Studies in the Spanish Language

\section{Dirección}

Pedro Jesús Teruel, Universitat de València

pedro.teruel@uv.es

Hernán Pringe, CONICET-Universidad de Buenos Aires/

Universidad Diego Portales, Santiago de Chile

hpringe@gmail.com

\section{Secretario de edición}

Fernando Moledo, CONICET-Universidad de Buenos Aires

fernandomoledo@filo.uba.ar

\section{Secretaria de calidad}

Marcela García, Universidad de Morelia, México

garciar.marcela@gmail.com

\section{Editores científicos}

Jacinto Rivera de Rosales, UNED, Madrid

Claudia Jáuregui, Universidad de Buenos Aires

Vicente Durán, Pontificia Universidad Javeriana, Bogotá

Julio del Valle, Pontificia Universidad Católica del Perú, Lima

Jesús Conill, Universitat de València

Gustavo Leyva, Universidad Autónoma de México, México D. F.

María Xesús Vázquez Lobeiras, Universidade de Santiago de Compostela

Wilson Herrera, Universidad del Rosario, Bogotá

Pablo Oyarzun, Universidad de Chile, Santiago de Chile

Paula Órdenes Azúa, Universität Heidelberg 


\section{Comité científico}

Juan Arana, Universidad de Sevilla

Reinhardt Brandt, Philipps-Universität Marburg

Mario Caimi, Universidad de Buenos Aires

Monique Castillo, Université de Paris-Est

Adela Cortina, Universitat de València

Bernd Dörflinger, Universität Trier

Norbert Fischer, Universität Eichstätt-Ingolstadt

Miguel Giusti, Pontificia Universidad Católica del Perú

Dulce María Granja, Universidad Nacional Autónoma de México

Christian Hamm, Universidad Federal de Santa María, Brasil

Dietmar Heidemann, Université du Luxembourg

Otfried Höffe, Universität Tübingen

Claudio La Rocca, Università degli Studi di Genova

Juan Manuel Navarro Cordón, Universidad Complutense, Madrid

Carlos Pereda, Universidad Nacional Autónoma de México

Gustavo Pereira, Universidad de la República, Uruguay

Ubirajara Rancan de Azevedo, Universidade Estadual Paulista, Brasil

Margit Ruffing, Johannes Gutenberg-Universität Mainz

Gustavo Sarmiento, Universidad Simón Bolívar, Venezuela

Sergio Sevilla, Universitat de València

Roberto Torretti, Universidad Diego Portales, Santiago de Chile

Violetta Waibel, Universität Wien

Howard Williams, University of Aberystwyth

Allen W. Wood, Indiana University

Diseño, editor de estilo y maqueta

Josefa Ros Velasco, Universidad Complutense de Madrid

\section{Entidades colaboradoras}

Sociedad de Estudios Kantianos en Lengua Española (SEKLE)

Departament de Filosofia de la Universitat de València

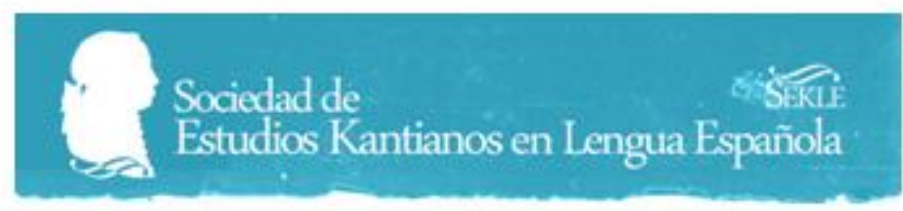




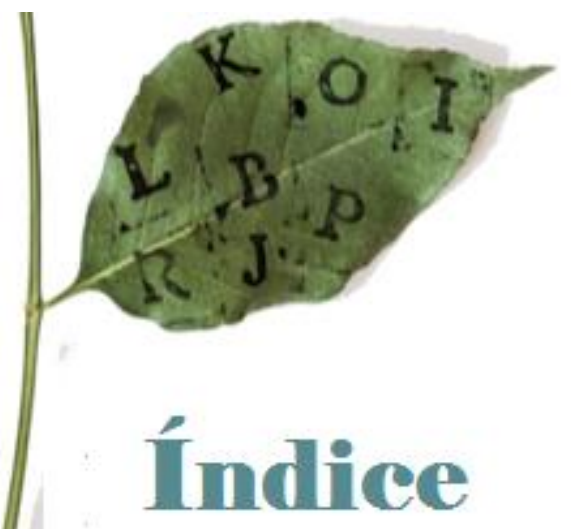

\section{Artículos}

9 Pensar como operación - Acerca de los presupuestos e implicaciones de la lógica formal moderna

Max Gottschlich

DOI 10.7203/REK.2.1.10059

20 Los conceptos kantianos de "facultad" y de "mente" frente a la lectura epigenética Antonino Falduto

DOI 10.7203/REK.2.1.10011

29 Arqueología filosófica y hermenéutica. Apuntes sobre la interpretación de la historia de la filosofía en Kant

José García Gómez del Valle

DOI 10.7203/REK.2.1.8811

48 Continuidad y novedad en la concepción histórica de Kant en El conflicto de las facultades Natalia Lerussi

DOI 10.7203/REK.2.1.9892

60 It's impossible to will to be punished? Exploring consensual way out of the Kantian dilema Matías Parmigiani

DOI 10.7203/REK.2.1.8813

\section{Recensiones}

89 Immanuel Kant (trad. Alba Jiménez): Lecciones de filosofía moral Mrongovius II. Salamanca, Sígueme, 2017, 160 pp. ISBN: 978-8-4301-1954-7

Pablo Veraza Tonda

DOI 10.7203/REK.2.1.9990 
91 Faviola Rivera Castro: Virtud, Felicidad y Religión en la Filosofía Moral de Kant. México, Instituto de Investigaciones Filosóficas-UNAM, 2014, 328 pp. ISBN: 978-607-02-4788-0

Gustavo Leyva

DOI 10.7203/REK.2.1.9992

93 Vicente de Haro Romo: Duty, Virtue and Practical Reason in Kant's Metaphysics of Morals. Hildesheim/Zürich/New York, Georg Olms Verlag, 2015, 342 pp. ISBN: 978-3487-15348-3

Eduardo E. Charpenel

DOI 10.7203/REK.2.1.9998

96 Paolo Grillenzoni: Kant e la scienza (1755-1760). Roma, Aracne, 2016, 575 pp. ISBN: 9788-854-89523-2

Daniele Savino

DOI 10.7203/REK.2.1.10054

100 Nuria Sánchez Madrid: A Civilização como destino. Kant e as formas da reflexão.

Florianópolis, Nefiponline, 2016, 288 pp. ISBN: 978-85-99608-16-6

Josefa Ros Velasco

DOI 10.7203/REK.2.1.9801

103 Laura Anna Macor: Die Bestimmung des Menschen (1748-1800): Eine Begriffsgeschichte. Forschungen und Materialien zur deutschen Aufklärung. Abteilung II: MonographienFMDA II, 25. Stuttgart-Bad Cannstatt, Frommann-Holzboog, 2013, 432 pp. ISBN: 978-37728-2615-3

Daniel Schwab

DOI 10.7203/REK.2.1.9989

\section{Informes}

109 Rezension zur Internationalen Tagung "Teleologische Reflexion in Kants Philosophie" Anna Pickhan (geb. Brechtel)

DOI 10.7203/REK.2.1.9993

\section{Entrevistas}

112 Entrevista a Pablo Muchnik

Fernando Moledo

DOI 10.7203/REK.2.1.10064

\section{Convocatorias y normas para autores}

118 Kant en México

DOI 10.7203/REK.2.1.10085

119 II Premio Kant para Jóvenes Investigadores e Investigadoras DOI 10.7203/REK.2.1.10086 
120 IV Congreso Internacional de la SEKLE, Valencia, 2018 DOI 10.7203/REK.2.1.10088

121 Normas para autores DOI 10.7203/REK.2.1.10091 


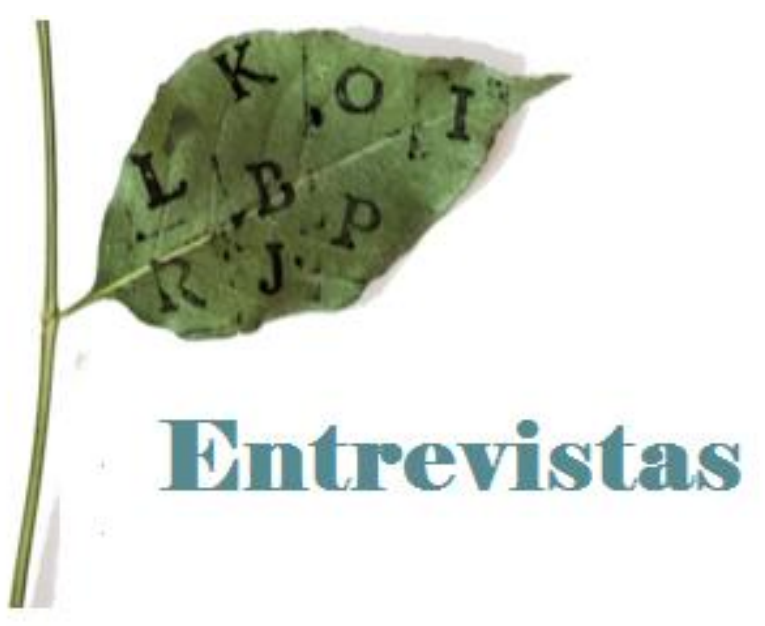




\title{
Entrevista a Pablo Muchnik (Emerson College)
}

\author{
FERNANDO MOLEDO ${ }^{1}$
}

Tenemos el agrado de acercar a nuestros lectores el diálogo mantenido con Pablo Muchnik, ${ }^{2}$ en el que hemos conversado sobre cuestiones relativas a la filosofía kantiana, pero también al desarrollo de la investigación kantiana en general y en español en particular.

Muchnik es profesor asociado en Emerson College y ha publicado numerosas investigaciones sobre la filosofía de Kant, con especial acento en la filosofía moral, política, y de la religión. Esautor de Kant's Theory of Evil: An Essay on The Dangers of Self-Love and the Aprioricity of History (Lexington Books, 2009), editor de los dos primeros volúmenes de Rethinking Kant (Cambridge Scholar Publishing, vol. I, 2008; vol. II, 2010) y coeditor de los volúmenes IV (2014) y V (de próxima aparición), así como también coeditor de Kant's Anatomy of Evil (Cambridge University Press, 2010). A su vez dirige dos colecciones: Kantian Questions (Cambridge Scholar Publishing) y Kant's Sources in Translation (Bloomsbury). Además, ha sido presidente de la North American Kant Society (2014-2017), después de haber servido como vice-presidente entre 2009-2014.

Fernando Moledo: Comencemos con las preguntas dirigidas a su interpretación de la filosofía de Kant. Usted se ha dedicado intensamente al estudio de la posición de Kant, sobre uno de los problemas más fascinantes de la historia de la filosofía: el problema del mal. ¿Cómo resumiría las tesis de Kant? O, dicho de otro modo: ¿en qué consiste, para usted, la esencia del concepto kantiano del mal?

Pablo Muchnik: En contra de las interpretaciones consecuencialistas que conciben el mal en términos del impacto que tienen los actos perniciosos, para Kant el mal designa el tipo de voluntad que subyace y hace posible la inmoralidad en todas sus formas. Tal estructura volicional está presente tanto en los actos observables de transgresión moral (en la agresión, la violencia, la opresión, la humillación, etc.), como en los subterfugios del auto-engaño, que corrompen el juicio moral, pero son invisibles a los ojos. En todos los casos, "malo" es el hombre que erige al amor propiocomo criterio fundamental para determinar su conducta, y por lo tanto cumple con su deber siempre y cuando éste no se interponga a su felicidad. Para Kant, esta actitud de obediencia condicional expresa una disposición moral en la que el agente ha invertido el orden ético de prioridades, de acuerdo al cual el deber es un incentivo autosuficiente, capaz de ponerun límite a las inclinaciones y subordinarlas a los dictados de la ley.

La maldad designa, así, una forma auto-impuesta de incorregibilidad moral: el hombre malo se rehúsa a someter su concepción subjetiva del bien (su felicidad) al examen objetivo de la moralidad. Sus deseos e inclinaciones son la medida de todas las cosas, soslayando no sólo cómo afectan a la capacidad de otros agentes para determinar sus propios fines, sino también, y de modo más esencial todavía, ignorando cómo tal actitud corrompe su propia capacidad de agencia. Pues, al otorgar prioridad volicional al deseo irrestricto, el sujeto somete su racionalidad a su sensibilidad y transforma su autonomía en heteronomía -en suma, la primacía al amor propio socava el fundamento mismo de la dignidad humana. Para Kant, la instrumentalización y reificación de otros agentes son siempre precedidas por un acto de auto-destrucción moral.

${ }^{1}$ Universidad de Buenos Aires - CONICET

${ }^{2}$ Web oficial: https://www.emerson.edu/academics/faculty-guide/profile/pablo-muchnik/2954 
Lo más interesante de la concepción kantiana es, en mi opinión, que la maldad así entendida puede ser perfectamente asintomática, compatible con la legalidad de las acciones. Tal como sugiere el ejemplo del comerciante en la Fundamentación, es imposible distinguir al hombre bueno del hombre de buena conducta, pues los dictados del amor propio y las prescripciones del deber tienden a coincidir en la sociedad contemporánea. Inspirado por Rousseau, Kant sostiene que el progreso de la civilización y la consolidación del poder coercitivo del Estado han hecho del hombre una criatura calculadora, eficiente en ocultar su inmoralidad más profunda. Por eso concluye en la Paz Perpetua que demonios inteligentes pueden constituir un pueblo de ciudadanos ejemplares. Para Kant, las leyes sociales no erradican al mal, sino que lo perpetúan bajo la "apariencia de la virtud" (Tugendschein). Esta disimulación en masa hace del mal un "enemigo invisible, que se esconde detrás de la razón, y es por ello aún más peligroso" (RGV AA 6:57).

La persistencia de la guerra, la opresión, la crueldad, y la infinidad de atrocidades que los hombres cometen unos contra otros, nos recuerdan que la batalla moral no concluye con la victoria política -apenas comienza allí. La ética kantiana contiene así la clave para comprender mejor los males que afligen al mundo, y nos prepara para combatirlos, pues denuncia la ceguera de quienes confían que el liberalismo político y el progreso económico pueden, por sí mismos, transformar la moralidad de los hombres.

Fernando Moledo: El punto de vista de Kant acerca del hombre, su visión antropológica en sentido fuerte (moral), parece oscilar entre dos grandes ideas: a) El concepto de la buena voluntad, como un bien absoluto que no sólo tiene valor normativo, sino que incluso da sentido a la creación misma.b) El mal radical, esto es, la concepción acerca de la corrupción fundamental de la voluntad humana. ¿Qué piensa Kant realmente sobre el hombre? ¿Es bueno? ¿Es malo?

Pablo Muchnik: La especie humana para Kant exhibe una disonancia fundamental: aunque el hombre es malo por naturaleza, está teleológicamente orientado hacia el bien. El hombre es malo, pues se le puede atribuir, incluso al más virtuoso, una propensión a dar a su amor propio un valor desmesurado. Esta es una tendencia básica, primordial, presente en nuestra voluntad desde que tenemos memoria, que nos lleva a acomodar las demandas estrictas del deber a los caprichos de las inclinaciones. Para tener valor moral, sin embargo, esta tendencia no puede ser entendida como resultado de una determinación meramente biológica -los genes son "moralmente inertes", ni buenos ni malos. Sólo de aquello de lo que somos autores se nos puede imputar.

Ahora bien, para ser imputable un acto debe ser libre. Pero el concepto de "libertad" es para Kant incomprensible fuera de su relación con la ley moral, pues es la conciencia de la ley la que nos alerta de la presencia de una forma de causalidad independiente de la naturaleza. En la ética kantiana, "libertad" y "moralidad" son conceptos que se implican mutuamente. Esta relación tiene consecuencias fundamentales para la antropología: se sigue de ella que es imposible concebir al ser humano como una criatura diabólica, capaz de hacer el mal por el mal mismo. Pues si la maldad fuera un incentivo autosuficiente, podríamos constituir nuestro carácter moral a espaldas de la ley, en un rechazo absoluto de las constricciones de la racionalidad práctica. Pero tal rechazo es incompatible con la libertad y convertiría al agente en un autómata, más allá del bien y del mal, sin responsabilidad alguna por sus acciones. En tanto criatura libre, por lo tanto, el ser humano no puede ignorar por completo el dictado de la ley, y con ello la agonía de elegir la forma que dará a su voluntad. Este es un dilema que el diablo y los ángeles desconocen. Por ello, Kant concluye, aún el peor de los hombres "no repudia la ley moral [...] en actitud de rebeldía (revocando toda obediencia a ella). La ley se impone a sí misma sobre él irresistiblemente, debido a su predisposición moral, y si otro incentivo no la contradijera, la incorporaría en su máxima suprema como determinación suficiente de su arbitrio" (RGV AA 6:36).

El hombre padece, entonces, de una dualidad constitutiva: la propensión al mal, que expresa los intereses de su amor propio, coexiste con una predisposición al bien, que expresa los intereses de la moralidad. Ambas tendencias son igualmente naturales, pero empujan a la voluntad en direcciones opuestas y la fuerzan a elegir darle prioridad a alguna de ellas. Esta elección determina nuestra identidad moral, pero no cancela la fractura interior, la disonancia fundamental con la cual Kant describe la condición humana. Por más arraigada que sea la propensión al mal, la obligación de erradicarla nos confronta con implacable urgencia. Esta confrontación es para Kant la condición de posibilidad de la formación de la conciencia moral, a la vez que cumple un papel esencial en la 
educación ética. Pues, suponer la presencia de una maldad natural de la que nadie está exento, nos lleva a establecer una constante vigilancia contra ella.

Fernando Moledo: ¿La clave para explicar la complejidad que Kant le atribuye a la naturaleza humana estaría entonces en el concepto de propensión al mal, que, a pesar de su radicalidad, sería perfectamente compatible con una disposición moral en el hombre?

Pablo Muchnik: Para entender la lógica interna de la posición kantiana es necesario distinguir dos nociones que los intérpretes normalmente confunden: "propensión al mal" (Hang zum Bösen), un concepto que Kant aplica para describir el carácter moral de la especie humana en su conjunto, y "disposición" (Gesinnung), un concepto que Kant utiliza para describir la orientación moral de un individuo en particular. A diferencia de la "propensión al mal" en la especie, la "disposición" individual puede ser buena o mala, según la forma que le hayamos dado a nuestra voluntad. Bueno es el agente que da primacía al deber sobre el amor propio, malo quien lo subordina. "Propensión" y "disposición" son, entonces, nociones que se refieren a unidades de análisis distintas: la primera tiene aplicación antropológica global; la segunda se restringe al ámbito de la moralidad individual.

Para ser imputables, tanto la propensión (en la especie) como la disposición (en el individuo) deben ser concebidas como actos de libertad relativamente independientes. De no ser así, la mera afiliación biológica de un agente, y no su libertad, determinaría su carácter. Es por ello que, aunque podamos caracterizar a la especie humana en su conjunto como "mala por naturaleza", los individuos que la componen pueden, sin embargo, ser buenos, i.e., tener una buena "disposición."

A diferencia de la visión agustiniana del pecado original, que corrompe no sólo nuestra voluntad, sino también nuestra capacidad de conocer el bien, el pesimismo antropológico kantiano es compatible con el optimismo moral. No hay contradicción entre ellos, pues cada unidad de análisis posee un tipo característico de obligación y de teleología, cuya fuerza normativa no desaparece, incluso en el caso de la desobediencia más extrema. La propensión al mal, interpretada de este modo, es expresión de un fracaso colectivo en obedecer al deber que la especie tiene de realizar el bien supremo; una mala disposición, en cambio, indica el fracaso, a nivel individual, en limitar la felicidad personal a las condiciones impuestas por el imperativo categórico. Mientras que del primer fracaso el individuo es parcialmente responsable, pues la realización del bien supremo depende de la cooperación de todos los hombres, frente al segundo fracaso no hay excusa posible, pues la conciencia de la ley es un Faktumder Vernunft, incorruptible e inextirpable.

En la Religión, Kant llama a este Faktum "personalidad", la tercera de las predisposiciones hacia el bien (Anlage zum Guten) con las que Kant describe la naturaleza humana y su teleología. Junto con las propensiones al mal, las predisposiciones al bien constituyen un esquema conceptual independiente, de validez antropológica, distinto en sus objetivos y métodos al aparato conceptual a priori que fundamenta la moralidad a nivel individual. Gran parte de las confusiones teóricas que se le endilgan a Kant son el resultado del hecho de que sus intérpretes confunden los conceptos de "propensión al mal" y de "mala disposición," y los tratan como si fueran sinónimos. Esta confusión ignora la independencia relativa que Kant atribuye a las distintas unidades de análisis en su concepción del mal radical, y genera falsos problemas de interpretación. La consistencia de la posición kantiana depende, en la lectura que propongo, de trazar una distinción sistemática entre ellos.

Fernando Moledo: ¿Cómo cree usted entonces que debemos entender el "hecho inteligible" (RGV AA 6: 31) al que Kant se refiere para explicar la adopción de la máxima de máximas que consiste en privilegiar el amor propio por sobre la ley moral y corrompe nuestra voluntad? ¿Se trata de otro de los facta cuyo origen no podemos explicar y que debemos, en cambio, aceptar sin más?

Pablo Muchnik: El significado de "inteligible" varía, una vez más, según las distintas unidades de análisis. A nivel individual, Kant cree que podemos determinar a priori (con certeza) la maldad de un agente. Esta determinación resulta de una cadena de inferencias: de acciones cometidas con conciencia de su inmoralidad, debemos inferir la presencia de máximas malas que las hacen posible; y de un conjunto de tales máximas, debemos inferir, en segunda instancia, la presencia de una máxima suprema (un principio último de selección de máximas), como condición de posibilidad de la inmoralidad de las acciones observables. Este tipo de argumento regresivo, transcendental, efectuado desde el punto de vista de la tercera persona (del espectador), es típico en la filosofía kantiana. La 
disposición es "inteligible," en el sentido de que, aunque no exista intuición de ella, debemos aceptarla como condición sine qua non para explicar el fenómeno de los actos inmorales.

El sentido de "inteligible" cambia cuando pasamos de la tercera a la primera persona, y adoptamos la perspectiva del agente. Para Kant, todos los hombres están obligados a interrogar su corazón y descubrir su orientación moral fundamental -tienen el deber de conocerse a sí mismos. A través del autoconocimiento, el individuo es llevado a descubrir que su disposición es "innata" -no porque la naturaleza sea su causa, sino porque la disposición que él ahora posee, su identidad moral, ha estado presente en su voluntad desde el principio, desde su "nacimiento," por así decir. En este sentido, la disposición es "inteligible," pero no porque se la infiera con certeza (como en el caso del argumento transcendental por parte del espectador). Al contrario: en el ejercicio de la introspección, descubrimos que nuestra disposición es inescrutable, que la certeza respecto a ella siempre nos elude, pues no se trata de un objeto de conocimiento teórico, sino de un objeto de deseo, un anhelo que moviliza nuestra voluntad. En tanto tal, la disposición debe permanecer inasible para poder motivar la pregunta: “¿Quién soy yo (moralmente hablando)?” Para Kant, la respuesta que cada agente ofrece a esta pregunta insondable no está fundada en una verdad objetiva sobre su carácter -tal verdad transciende los límites del conocimiento, pues depende del misterio que es nuestra libertad. Está basada, en cambio, en una relación subjetiva que el agente establece con su pasado y con su presente, en un vínculo con su identidad moral en función del cual cada hombre decide su futuro -sus próximos pasos como autor de su persona.

Existe, por último, un tercer sentido de "inteligible", asociado con la propensión al mal y su función en la narrativa kantiana de progreso moral de la humanidad en su conjunto. Pasamos aquí a un tipo distinto de discurso: un discurso antropológico basado parcialmente en la observación de la conducta colectiva, pero inspirado en una teleología moral de naturaleza a priori, independiente de la investigación empírica. Podríamos llamar a este discurso "cuasi-transcendental" - un nombre artificial, apto para designar el abordaje sui generis, conceptualmente híbrido, característico de la antropología moral kantiana. Este abordaje combina elementos normativos a priori con generalizaciones empíricas, el lenguaje de la observación con el lenguaje del deber. Los componentes heterogéneos que lo constituyen son parte un esfuerzo por parte de Kant por generar una nueva concepción de la naturaleza humana, de acuerdo a la cual la identidad de la especie no es un datum (como lo es en la antropología física), ni una posibilidad (como lo es en la antropología pragmática), sino un desideratum - una expresión de deseo, una tarea. La propensión al mal, entendida en este contexto, es "inteligible" en el sentido de que funciona como contrapunto al fin último de la historia, al destino moral del hombre. Tanto el telos como el punto de partida funcionan como herramientas heurísticas, como principios regulativos para generar una narrativa coherente de la trayectoria moral humana. En la medida en que Kant considera a la especie no sólo como autor de su carácter, sino también como responsable por realizar su futuro, el tercer sentido de "inteligible" combina elementos de los dos significados anteriores: la perspectiva del espectador se combina aquí con la del agente. Pero se trata ahora de un agente colectivo, cuyo campo de acción es la historia universal, no de un individuo particular, a cargo de su propia vida.

Fernando Moledo: Kant parece resignificar el concepto filosófico del mal, al darle un fundamento que no requiere apelar a concepciones teológicas propias de la metafísica dogmática tradicional, ni tampoco a una teoría naturalista sobre el hombre, de tipo empírico. ¿Lo cree usted de este modo? Si es así, ¿Cuál es, según su parecer, el aporte novedoso que la doctrina kantiana del mal proporciona a la tradición filosófica?

Pablo Muchnik: Efectivamente, uno de los aspectos más innovadores de la antropología moral reside en su concepción de la naturaleza humana: el hombre no es concebido ni como criatura de Dios, ni como producto de las fuerzas ciegas de la naturaleza; el ser humano debe, en cambio, concebirse a sí mismo como responsable absoluto de su carácter moral. Tanto la ciencia como la teología dogmática, Kant sostiene, son incapaces de hacer justicia a la autonomía humana, pues conciben al hombre en función de un modelo externo (el orden natural o el orden divino), que debemos imitar y al que debemos obediencia. Kant rehúsa aceptar esta visón heterónoma de la humanidad e introduce una revolución copernicana en el concepto de "naturaleza humana," de acuerdo a la cual no existe autoridad más sagrada que la ley moral dentro de nosotros mismos, ni objeto de respeto más alto que la dignidad de nuestros semejantes, ni ofensa más grande que la que destruye nuestra agencia. Para poder responder a la pregunta “¿Qué es el hombre?” debemos abandonar la práctica infantil, iniciada 
por Platón y continuada por el cristianismo tradicional, de invocar poderes superiores, ajenos, que nos impiden tomar responsabilidad plena por nuestro destino. Debemos, en cambio, correr el riesgo de pensar por nosotros mismos, sin la guía de otros, y asumir el coraje de vivir de acuerdo a nuestras propias luces, obedeciendo nuestra propia ley.

Fernando Moledo: ¿En qué medida, si es que lo es, la concepción kantiana del mal resulta filosóficamente fructífera hoy en día?

Pablo Muchnik: La promesa de la concepción kantiana, creo, reside en dos ámbitos principales. El primero es de carácter práctico, y concierne, tal como sugerí al principio de nuestra entrevista, la necesidad de combatir la ilusión de quienes identifican el progreso moral con la reducción de la crueldad. Para Kant, tal identificación, típica del utilitarismo y de los liberales del miedo (Shklar, Rorty, Rawls, etc.), sirve simplemente para enmascarar la seriedad del problema, y perpetúa el "letargo moral" al que somos tan proclives. El segundo es de carácter teórico, y concierne el desarrollo de las consecuencias conceptuales de la antropología moral, un campo de estudios que Kant inició en la Religión y esbozó en sus escritos sobre historia, pero que dejó fundamentalmente inacabado, ofreciéndonos piezas sueltas de un esquema conceptual cuya coherencia debemos todavía establecer. La idea de una revolución copernicana inconclusa en el concepto de "hombre" nos ofrece una alternativa teórica, un nuevo paradigma, para cuestionar la hegemonía de las ciencias naturales, y el platonismo que aún domina buena parte de la ética contemporánea.

Fernando Moledo: A lo largo de nuestra entrevista se refirió varias veces a la idea de una antropología moral, que no coincidiría, ciertamente, con la antropología en sentido pragmático. Es ella, a saber, la antropología moral, la que debe responder, pues, la pregunta fundamental "¿qué es el hombre?" ¿Sería parte de esa respuesta la doctrina que usted expuso, acerca de la disonancia fundamental en el hombre, que se encuentra entre la propensión natural al mal y la disposición moral?

Pablo Muchnik: Exactamente: tal como Kant indica en las lecciones de Lógica, de las preguntas esenciales que afligen a la razón humana (“¿Qué puedo conocer?”, “¿Qué debo hacer?”, “¿Que puedo esperar?"), la más decisiva, la que contiene la clave para responder al resto, es la pregunta: "Qué es el hombre?" Sería un error ceder a la epistemología (o las ciencias naturales), a la moral individual, o la a religión racional nuestra responsabilidad de darle una respuesta a esa pregunta. La respuesta debe originarse en esta ciencia híbrida, que yo llamo "antropología moral" para distinguirla de otros tipos de discursos que nos son más familiares. Su promesa consiste en concebir un nuevo tipo de agencia una agencia colectiva, universal, que involucra a todos los hombres. Pues sólo entendiendo la posibilidad y los límites de este tipo de agencia la humanidad podrá confrontar las consecuencias de su indeterminación biológica, del hecho de que la naturaleza del animal "hombre" consiste en no tener "naturaleza" y que por lo tanto su futuro depende exclusivamente de lo que, como ser parcialmente racional, decida hacer de sí mismo. La crisis ecológica que confronta actualmente la humanidad, la creciente desigualdad entre ricos y pobres, el problema endémico de la guerra y la violencia, etc., requieren precisamente del tipo de coordinación y de agencia que Kant esbozó, de manera más sistemática que sus predecesores (particularmente Rousseau) y más sobria que la de muchos de sus contemporáneos (particularmente Herder y Hegel), en las páginas de la Religión y en su filosofía de la historia.

Fernando Moledo: Ahora cambiemos un poco el eje de nuestra charla. Su lengua materna es el español. Sin embargo, ha realizado la mayor parte de su carrera en el ámbito anglo-parlante, concretamente en los Estados Unidos. Incluso ha actuado como presidente, hasta este año, de la North American Kant Society (NAKS). Estoy muy tentado de preguntarle, entre el bien y el mal, dónde situaría usted a las sociedades kantianas... Pero no lo haré. Mejor quisiera preguntarle qué ha significado para usted la experiencia del trabajo en una lengua que originalmente no era la suya.

Pablo Muchnik: El verme obligado a pensar y enseñar en otro idioma me forzó a tomar distancia respecto a los textos que amo, a estudiarlos siempre con un dejo de extrañamiento, como un etnógrafo que ha pasado gran parte de su vida en una tribu, habla con fluidez su idioma, pero no es del todo de la tribu. Esta posición liminal, creo, me ha dado una cierta independencia intelectual, pero su precio ha sido un mayor grado de vulnerabilidad profesional que la de muchos de mis colegas nativos. La academia norteamericana es tremendamente competitiva, y me he tenido que abrir paso a fuerza de perseverancia, buena suerte, y pasión por la filosofía, sin contar con los beneficios de formar parte de algún "clan". El hecho de haber sido elegido Presidente de la NAKS ha sido para mí una especie de 
rito de pasaje, de aceptación en el grupo. Aunque permanezco en lo personal un outsider marcado por mi origen en otra tierra y en otra cultura, me siento profundamente honrado por este gesto de aceptación en la tribu, pues muchos de los kantianos que más admiro en el mundo han ocupado este mismo cargo.

Fernando Moledo: ¿Cuáles son actualmente los proyectos más importantes de la NAKS?

Pablo Muchnik: NAKS ha experimentado un crecimiento enorme en los últimos años: tenemos cientos de miembros, grupos de estudios en todas las regiones de Estados Unidos, premios para graduados y profesores en distinto estadio de desarrollo profesional, una colección de libros propia, presencia activa en las tres divisiones de la Asociación Filosófica Americana (APA), y una relación estrecha con muchas sociedades kantianas alrededor del mundo. En mi gestión, he tratado de crear una cultura institucional más inclusiva e igualitaria, más meritocrática y menos elitista, más cosmopolita y abierta a los debates que ocurren fuera de la tradición alemana y angloparlante. Mi deseo es que los nuevos líderes de la sociedad continúen trabajando en la misma dirección, y profundicen los vínculos internacionales que venimos forjando. 